Pacific Journal of Mathematics

ON THE GENERALIZED F. AND M. RIESZ THEOREM 


\title{
ON THE GENERALIZED F. AND M. RIESZ THEOREM
}

\author{
P. R. AHERN
}

Let $X$ be a compact Hausdorff space, $C(X)$ the algebra of all continuous complex valued functions on $X$, and let $A$ be a sup-norm algebra on $X$, that is, $A$ is a uniformly closed algebra of continuous complex valued functions on $X$ that contains the constants and separates the points. If $\phi$ is a complex homomorphism of $A$ then let $M(\phi)$ be the set of all positive, regular, Borel measures on $X$ that represent $\phi$. If $\mu$ is a finite, (complex), regular, Borel measure on $X$ then we write $\mu \perp A$ if $\int f d \mu=0$ for all $f \in A$. Let $\phi$ be a complex homomorphism of $A$ and $m \in M(\phi)$, then we say that $m$ satisfies the Riesz theorem if whenever $\mu$ is a finite, (complex), regular, Borel measure on $X$ and $\mu \perp A$ then $\mu_{a} \perp A$ and $\mu_{s} \perp A$ where $\mu=\mu_{a}+\mu_{s}$ is the Lebesgue decomposition of $\mu$ with respect to $m$. It is quite easy to see that if $m \in M(\phi)$ and $m$ satisfies the Riesz theorem then for all $\rho \in M(\phi)$ we have $\rho$ is absolutely continuous with respect to $m$. We will show that this condition is also sufficient. This is done by means of a theorem which says that if $F \cong X$ is a compact $G_{\delta}$ such that $m(F)=0$ for all $m \in M(\phi)$ then there exists a sequence $f_{n}$ in $A$ such that $\left|f_{n}\right| \leqq 1$ on $X, \phi\left(f_{n}\right) \rightarrow 1$, and $f_{n} \rightarrow 0$ uniformly on $F$.

The proof given is not a generalization of the modern proof of the F. and M. Riesz theorem as given in [4], for instance, but is closer in form to the original proof of F. and M. Riesz. If $X=S_{1} \cup S_{2}$ is the decomposition of $X$ corresponding to the decomposition $\mu=$ $\mu_{a}+\mu_{s}$, then by means of Theorem 1 we find a bounded sequence in $A$ that converges to the characteristic function of $S_{1}$ almost everywhere with respect to the total variation of the measure $\mu$. It is known (see Hoffman [4] and Lumer [5]) that if $M(\phi)=\{m\}$ then the Riesz theorem holds for the measure $m$. It is known that $M(\phi)$ is not empty [4].

It what follows, all measures are assumed to be finite, regular, Borel measure, and $\phi$ is a fixed complex homomorphism of $A$.

LEMMA 1. Let $\left\{\nu_{n}\right\}$ be a sequence of positive measures on $X$ having the measure $m$ as a weak-star accumulation point. Suppose $F \subseteq Y$

Received April 7, 1964. Supported by National Science Foundation postdoctoral fellowship. 
is compact and that $\nu_{n}(F) \geqq \varepsilon_{0}>0$ for all $n$. Then $m(F) \geqq \varepsilon_{0}$.

Proof. There exists a decreasing sequence of open sets $\mathscr{O}_{n} \supseteqq F$ such that $m\left(O_{n}-F\right) \rightarrow 0$. There exists a sequence $u_{n}$ of continuous real valued functions such that $u_{n}=1$ on $F, u_{n}=0$ on $X-\mathscr{O}_{n}$ and $0 \leqq u_{n} \leqq 1$ elsewhere. From the construction, $u_{n} \rightarrow \chi_{F}$ a.e. $(m)$, where $\chi_{F}$ is the characteristic function of $F$. So we have,

$$
m(F)=\int\left(\chi_{F}-u_{k}\right) d m+\int u_{k} d \nu_{n}+\int u_{k}\left(d m-d \nu_{n}\right) .
$$

Note that $\int u_{k} d \nu_{n} \geqq \nu_{k}(F) \geqq \varepsilon_{0}$ for all $n$ and $k$. Now, $\int\left(\chi_{F}-u_{k}\right) d m$ can be made small by choosing $k$ large, and once $k$ is fixed $\int u_{k}\left(d m-d \nu_{n}\right)$ can be made small by proper choice of $n$. This proves the lemma.

The proof of the next lemma can be found in [1], Theorem 3.b.

Lemma 2. Let $u \in C(X)$ be real valued and suppose

$$
\begin{aligned}
\sup \{R e \phi(g) \mid R e g & \leqq u, g \in A\} \\
& \leqq \gamma \leqq \inf \{\operatorname{Re} \phi(g) \mid \operatorname{Reg} \geqq u, g \in A\}
\end{aligned}
$$

then there exists $\rho \in M(\phi)$ such that $\int u d \rho=\gamma$. In particular, there exists $\rho_{u} \in M(\phi)$ such that

$$
\sup \{R e \phi(g) \mid \operatorname{Re} g \leqq u, g \in A\}=\int u d \rho_{u} .
$$

THeOREM 1. Let $F \subseteq X$ be a compact $G_{\delta}$ such that $m(F)=0$ for all $m \in M(\phi)$, then there exists a sequence $f_{n} \in A$ such that

(1) $\left|f_{n}\right| \leqq 1$ on $X$.

(2) $\phi\left(f_{n}\right) \geqq e^{-2 / n}$.

(3) $\left|f_{n}\right| \leqq e^{-n}$ on $\boldsymbol{F}$.

Proof. Since $F$ is a compact $G_{\delta}$, there is a sequence of open sets $\left\{\mathscr{O}_{n}\right\}$ such that $\overline{\mathcal{O}}_{n+1} \cong \mathscr{O}_{n}$ and $\bigcap_{n} \mathscr{O}_{n}=F$. Let $\varepsilon>0$ be given, then there exists an integer $N$ such that for all $n \geqq N, \rho\left(\mathscr{O}_{n}\right)<\varepsilon$ for all $\rho \in M(\phi)$. For suppose this were not true, then there would exist $\varepsilon_{0}>0$ and sequences $\rho_{k} \in M(\phi)$ and $\mathcal{O}_{n_{k}}$ such that $\rho_{k}\left(\mathcal{O}_{n_{k}}\right) \geqq \varepsilon_{0}$ Let $U_{k}=\mathscr{O}_{n_{k}}$ then we have $\rho_{k}\left(U_{k}\right) \geqq \varepsilon_{0}>0$ and $\bar{U}_{k+1} \subseteq U_{k}$. The sequence $\rho_{k}$ has a weak-star limit point $\rho$, and it is well known that $\rho \in M(\phi)$ hence $\rho(F)=0$. Fix $k$, then $\rho\left(U_{k}\right) \geqq \rho\left(\bar{U}_{k+1}\right)$, now $\rho_{n}\left(\bar{U}_{k+1}\right) \geqq \rho_{n}\left(U_{k+1}\right) \geqq$ $\rho_{n}\left(U_{n}\right) \geqq \varepsilon_{0}>0$ for all $n \geqq k+1$. Therefore by Lemma 1 we have $\rho\left(U_{k}\right) \geqq \varepsilon_{0}>0$ for all $k$. But this contradicts the fact that $\rho(F)=0$. Hence by proper choice of subsequence we may assume that $\rho\left(\mathcal{O}_{n}\right)<\left(1 / n^{2}\right)$ 
for all $\rho \in M(\phi)$. Now for each $n$ there exists $u_{n} \in C(X)$ such that $u_{n}=-n$ on $F, u_{n}=0$ on $X-\mathscr{O}_{n}$ and $-n \leqq u_{n} \leqq 0$ elsewhere. By Lemma 2, there exists $\rho_{n} \in M(\phi)$ such that

$$
\sup \left\{R e \phi(g) \mid R e g \leqq u_{n}, g \in A\right\}=\int u_{n} d \rho_{n},
$$

and hence for each $n$ there exists $g_{n} \in A$ such that $R e g_{n} \leqq u_{n}$ and

$$
\int R e g_{n} d m \geqq \int u_{n} d \rho_{n}-\frac{1}{n} \geqq-n \rho_{n}\left(O_{n}\right)-\frac{1}{n} \geqq-\frac{2}{n} .
$$

We may also assume that $\int I m g_{n} d m=0$. If we now define $f_{n}=e^{g_{n}}$ it follows that

(1) $\left|f_{n}\right|=e^{R e g_{n}} \leqq e^{u_{n}} \leqq 1$

(2) $\int f_{n} d m=\exp \left[\int g_{n} d m\right]=\exp \left[\int R e g_{n} d m\right] \geqq e^{-2 / n}$

(3) $\left|f_{n}\right|=e^{R e g_{n}} \leqq e^{-n}$ on $F$.

The sequence $\left\{f_{n}\right\}$ of Theorem 1 is bounded in norm by 1 , yet $\phi\left(f_{n}\right) \rightarrow 1$. We show that this implies that $\psi\left(f_{n}\right) \rightarrow 1$ for all $\psi$ in the same part as $\phi$. For definition of part see [4]. For this we use a result of Bishop [2]: if $\phi, \psi$ are in the same part and $m_{\phi}$ is a representing measure for $\phi$, then there exists a representing measure $m_{\psi}$ for $\psi$ such that $m_{\phi} \leqq A m_{\psi}$ for some constant $A$.

CoRollary 1. If $\left\{f_{n}\right\}$ is the sequence of Theorem 1 and $\psi$ is in the same part as $\phi$, then $y^{\prime}\left(f_{n}\right) \rightarrow 1$.

Proof. Let $m$ be a representing measure for $\psi$, and $\rho$ be a representing measure for $\phi$ such that $m \leqq A \rho$ for some constant $A$. Then we have $m=g \rho$ where $g$ is bounded. Since $\psi\left(f_{n}\right) \rightarrow 1$ we have $\int f_{n} d \rho \rightarrow 1$. This, together with the fact that $\left|f_{n}\right| \leqq 1$ implies that $f_{n} \rightarrow 1$ in measure, with respect to the measure $\rho$. Since $g$ is bounded it follows that $f_{n} g \rightarrow g$ in measure with respect to the measure $\rho$. The fact that $\left|f_{n} g\right| \leqq|g|$ now implies that $\psi\left(f_{n}\right)=\int f_{n} g d \rho \rightarrow \int g d \rho=\int d m=1$.

CoRollary 2. Suppose there is a measure $m \in M(\phi)$ such that $\rho \ll m$ for all $\rho \in M(\phi)$, and suppose $F \subseteq X$ is compact and $m(F)=0$. Then there exists a sequence $f_{n} \in A$ satisfying (1), (2), (3) of Theorem 1.

Proof. There exists a sequence $\left\{\mathcal{O}_{n}\right\}$ of open sets such that $F \subseteq$ $\mathscr{O}_{n+1} \subseteq \mathscr{O}_{n}$ and $m\left(\mathscr{O}_{n}\right) \rightarrow 0$. For each $n$, there exists a set $F_{n}$ which is a compact $G_{\delta}$ such that $F \subseteq F_{n} \subseteq \mathcal{O}_{n}$. Let $F_{1}=\bigcap_{n} F_{n}$, then $F \cong F_{1}$, 
$F_{1}$ is a compact $G_{\delta}$ and $m\left(F_{1}\right)=0$. It follows that $\rho\left(F_{1}\right)=0$ for all $\rho \in M(\phi)$. Now apply Theorem 1 to the set $F_{1}$.

THEOREM 2. Suppose there exists $m \in M(\phi)$ such that $\rho \ll m$ for all $\rho \in M(\phi)$. Let $\mu \perp A$ and let $\mu=\mu_{a}+\mu_{s}$ be the Lebesgue decomposition of $\mu$ with respect to $m$. Then $\mu_{a} \perp A$ and $\mu_{s} \perp A$.

Proof. Let $S$ be a Borel set that carries $\mu_{s}$ and $m(S)=0$. Then there exists an increasing sequence $F_{n} \subseteq S$ of compact sets such that $\left|\mu_{s}\left(F_{n}\right) \rightarrow\right| \mu_{s} \mid(S)$, where $\left|\mu_{s}\right|$ denotes the total variation of $\mu_{s}$. For each $F_{n}$ we have a sequence $f_{n, k} \in A$ such that

(1) $\left|f_{n, k}\right| \leqq 1$.

(2) $\int f_{n, k} d m \geqq e^{-2 / k}$.

(3) $\left|f_{n, k}\right| \leqq e^{-k}$ on $F_{n}$.

Define $h_{n}=f_{n n}$ then we have:

(1') $\left|h_{n}\right|=\left|f_{n, n}\right| \leqq 1$.

(2') $\int h_{n} d m=\int f_{n, n} d m \geqq e^{-2 / n}$.

$\left(3^{\prime}\right) \quad\left|h_{n}\right|=\left|f_{n, n}\right| \leqq e^{-n}$ on $F_{n}$.

From $1^{\prime}$ and $2^{\prime}$ it follows that $h_{n} \rightarrow 1$ in measure with respect to $m$ and hence we have a subsequence $h_{n_{k}} \rightarrow 1$ a.e. $(m)$. From $3^{\prime}$ we have $h_{n_{k}} \rightarrow 0$ a.e. $\left(\left|\mu_{s}\right|\right)$. Hence $g_{k}=h_{n_{k}} \rightarrow \chi_{x-S}$ a.e. $(|\mu|)$. So if $f \in A$ then for each $k, g_{k} f \in A$ and we have $0=\int g_{n} f d \mu \rightarrow \int_{X-S} f d \mu=\int f d \mu_{a}$. This proves the theorem.

We point out that if the homomorphism $\phi$ has a representing measure $m$ such that $\rho \in M(\phi)$ implies $\rho \ll m$ then it follows easily from the result of Bishop mentioned earlier that every $\psi$ that lies in the same part as $\phi$ has a representing measure with this same property.

\section{REFERENCES}

1. H. Bauer, Silovcher Rand und Dirichlelsches Problem, Ann. Inst. Fourier (Grenoble) 11 (1961).

2. E. Bishop, Representing measures for points in a uniform algebra, Bull. Amer. Math. Soc. 70, 1 (1964).

3. F. Forelli, Analytic measures, Pacific J. Math. 13, 2 (1963).

4. K. Hoffman, Analytic functions and logmodular Banach algebras, Acta Math. 108 (1962).

5. G. Lumer, Analytic functions and Dirichlet problem, Bull. Amer. Math. Soc. 70, 1 (1964). 


\title{
PACIFIC JOURNAL OF MATHEMATICS
}

\author{
EDITORS
}

\author{
H. Samelson \\ Stanford University \\ Stanford, California \\ R. M. Blumenthal \\ University of Washington \\ Seattle, Washington 98105
}

\author{
J. DugundjI \\ University of Southern California \\ Los Angeles, California 90007 \\ Richard Arens \\ University of California \\ Los Angeles, California 90024
}

\section{ASSOCIATE EDITORS}
E. F. BECKENBACH
B. H. NEUMaNN
F. WOLF
K. YosIDA

\section{SUPPORTING INSTITUTIONS}

\author{
UNIVERSITY OF BRITISH COLUMBIA \\ CALIFORNIA INSTITUTE OF TECHNOLOGY \\ UNIVERSITY OF CALIFORNIA \\ MONTANA STATE UNIVERSITY \\ UNIVERSITY OF NEVADA \\ NEW MEXICO STATE UNIVERSITY \\ OREGON STATE UNIVERSITY \\ UNIVERSITY OF OREGON \\ OSAKA UNIVERSITY \\ UNIVERSITY OF SOUTHERN CALIFORNIA
}

\author{
STANFORD UNIVERSITY \\ UNIVERSITY OF TOKYO \\ UNIVERSITY OF UTAH \\ WASHINGTON STATE UNIVERSITY \\ UNIVERSITY OF WASHINGTON \\ AMERICAN MATHEMATICAL SOCIETY \\ CALIFORNIA RESEARCH CORPORATION \\ SPACE TECHNOLOGY LABORATORIES \\ NAVAL ORDNANCE TEST STATION
}

Mathematical papers intended for publication in the Pacific Journal of Mathematics should by typewritten (double spaced). The first paragraph or two must be capable of being used separately as a synopsis of the entire paper. It should not contain references to the bibliography. Manuscripts may be sent to any one of the four editors. All other communications to the editors should be addressed to the managing editor, Richard Arens, at the University of California, Los Angeles, California 90024.

50 reprints per author of each article are furnished free of charge; additional copies may be obtained at cost in multiples of 50 .

The Pacific Journal of Mathematics is published quarterly, in March, June, September, and December. Effective with Volume 13 the price per volume (4 numbers) is $\$ 18.00$; single issues, $\$ 5.00$. Special price for current issues to individual faculty members of supporting institutions and to individual members of the American Mathematical Society: $\$ 8.00$ per volume; single issues $\$ 2.50$. Back numbers are available.

Subscriptions, orders for back numbers, and changes of address should be sent to Pacific Journal of Mathematics, 103 Highland Boulevard, Berkeley 8, California.

Printed at Kokusai Bunken Insatsusha (International Academic Printing Co., Ltd.), No. 6, 2-chome, Fujimi-cho, Chiyoda-ku, Tokyo, Japan.

PUBLISHED BY PACIFIC JOURNAL OF MATHEMATICS, A NON-PROFIT CORPORATION

The Supporting Institutions listed above contribute to the cost of publication of this Journal, but they are not owners or publishers and have no responsibility for its content or policies. 


\section{Pacific Journal of Mathematics}

\section{Vol. 15, No. $2 \quad$ October, 1965}

Patrick Robert Ahern, On the generalized F. and M. Riesz theorem......... 373

A. A. Albert, On exceptional Jordan division algebras ................ 377

J. A. Anderson and G. H. Fullerton, On a class of Cauchy exponential

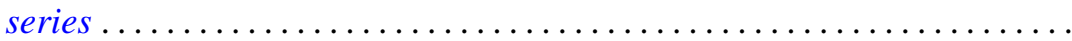

Allan Clark, Hopf algebras over Dedekind domains and torsion in

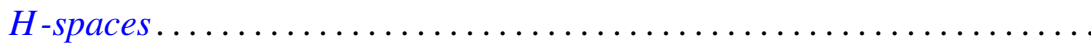

John Dauns and D. V. Widder, Convolution transforms whose inversion functions have complex roots .............................

Ronald George Douglas, Contractive projections on an $\mathrm{L}_{1}$ space ..........

Robert E. Edwards, Changing signs of Fourier coefficients ...............

Ramesh Anand Gangolli, Sample functions of certain differential processes on symmetric spaces .....................................

Robert William Gilmer, Jr., Some containment relations between classes of

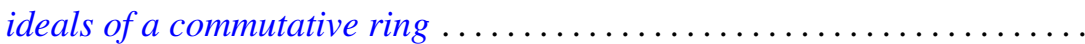

Basil Gordon, A generalization of the coset decomposition of a finite

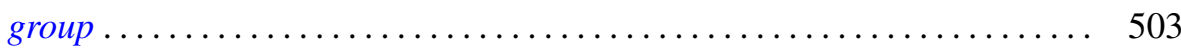

Teruo Ikebe, On the phase-shift formula for the scattering operator....... 511

Makoto Ishida, On algebraic homogeneous spaces ................ 525

Donald William Kahn, Maps which induce the zero map on homotopy ........ 537

Frank James Kosier, Certain algebras of degree one ................. 541

Betty Kvarda, An inequality for the number of elements in a sum of two sets of lattice points.................................

Jonah Mann and Donald J. Newman, The generalized Gibbs phenomenon for regular Hausdorff means. .

Charles Alan McCarthy, The nilpotent part of a spectral operator. II . ...

Donald Steven Passman, Isomorphic groups and group rings ...

R. N. Pederson, Laplace's method for two parameters .....

Tom Stephen Pitcher, A more general property than domination for sets of probability measures .............................

Arthur Argyle Sagle, Remarks on simple extended Lie algebras. .

Arthur Argyle Sagle, On simple extended Lie algebras over fields of

characteristic zero.

Tôru Saitô, Proper ordered inverse semigroups ...........

Oved Shisha, Monotone approximation

Indranand Sinha, Reduction of sets of matrices to a triangular form

Raymond Earl Smithson, Some general properties of multi-valued

functions .................................

John Stuelpnagel, Euclidean fiberings of solvmanifolds .... 